\title{
The Evolution of Distribution of Technology Transfer in China: Evidence from Patent Licensing
}

\author{
Yuqing Cai \\ School of Management, Jinan University, Guangzhou, China \\ Email: 15521219212@163.com
}

How to cite this paper: Cai, Y.Q. (2018) The Evolution of Distribution of Technology Transfer in China: Evidence from Patent Licensing. American Journal of Industrial and Business Management, 8, 1239-1252. https://doi.org/10.4236/ajibm.2018.85084

Received: April 16, 2018

Accepted: May 18, 2018

Published: May 21, 2018

Copyright $\odot 2018$ by author and Scientific Research Publishing Inc. This work is licensed under the Creative Commons Attribution International License (CC BY 4.0).

http://creativecommons.org/licenses/by/4.0/

\section{(c) (i) Open Access}

\begin{abstract}
This study explores the temporal and spatial distribution of technology transfer in China by analyzing the licensing activities from the perspective of supplier and demander of the technology transfer chain, using the data obtained from the State Intellectual Property Office of China (SIPO). We find that the overall number of licensed technologies has increased dramatically during 10 years and different types of technology show diverse trends. And the technology age is declining year by year, among which the age of invention patents is the oldest. As licensors, individuals and firms provide the vast majority of outward technologies and most of their technologies are utility models. However, only firms take the vast majority as licensee. And most inward technologies come from foreign organizations before 2008, while domestic sources provide the majority of inward technologies after 2008. We also provide suggestions for policy-makers and firms.
\end{abstract}

\section{Keywords}

Technology Transfer, Patent Licensing, China

\section{Introduction}

Learning from external technology sources through an effective technology market has been promoted as a primary means to overcome technological deficiencies at a national level [1]. Technology transfer has been one of the most important vehicles by which firms gain access to technological knowledge from developed economies [2]. Technology licensing is one of the most important means through which technology transfer is achieved. Many scholars have confirmed through empirical research that in-licensed technology from the outside 
can effectively improve their innovation performance [3] [4]. As a developing country, China acquires and absorbs advanced knowledge from developed countries, which is the key in filling its own technical gaps and catching up with other countries [5] [6]. Among them, patent licensing is an important channel for technology transfer.

The patent licensing activities represent the transfer of the right to use the patent from the licensor to the licensee, and it shows obvious directionality. From the perspective of the licensor, especially for developing countries, the in-licensed technology can provide strategic assets to make up for technological gaps and gain competitive advantage in the international market [7]. Therefore, patent licensing is widely considered one of the most important ways to transfer technology.

In the previous researches, the dimensions of knowledge transfer are generally drawn from temporal, spatial and geographical perspectives [8]. Liu and Ma explored the rules of knowledge creation activities at both temporal and spatial scales through a bibliometric view [9]. Chen provided a detailed analysis on the potentiality for alliances involving technology transfer between Chinese enterprises and Western companies, based on a questionnaire survey covering 200 sample companies and factories in mechanical industries in China [10].

However, most existing studies focused mainly on the supply of technology, but several other aspects of these markets remain under-studied, including the demand for technology and the dynamic interaction in the market for technology. We believe that these questions are becoming increasingly vital due to the stylized fact that the innovation paradigm has been shifting from closed innovation to open innovation, in which an increasing number of firms from both developed and developing countries are adopting external technology as their main innovation strategy [11] [12]. Thus, to address the aforementioned question, this study intends to empirically analyze the data obtained from the State Intellectual Property Office of China (SIPO) to explore the overall trends, the evolutions of temporal and geographical distributions of technology transfer represented by technology licensing activities from the perspectives of supplier and demander of the technology transfer chain respectively.

This study makes a contribution that it analyzes the temporal and geographical distribution of technology transfer, not only from the perspective of licensee, but also in terms of licensor, extending the existing literature on knowledge transfer. In practice, these findings have strong implications for policy-makers and firm managers about how to find, transfer and successfully commercialize the existing technologies generated by various agents in different places.

However, there are still a few limitations of this study. Firstly, this study only empirically analyzes the temporal and geographical distribution of technology transfer. Secondly, this article only explores the flow of knowledge through the patent licensing, while there are many other channels of technology transfer remaining to be investigated. Thirdly, it is difficult to update the data we use in this study, so we can only investigate the rule of the evolutions from 2002 to 
2012. Future research is needed to provide better investigation about this topic.

The next section introduces the data sources and methods used in this study. Section 3 presents the analysis results from the perspective of the licensor, while Section 4 from the perspective of the licensee. At last, this paper ends with discussion and conclusions.

\section{Technology Licensing Data and Methods}

Patent licensing refers to the way in which a patented technology owner can authorize another entity to use the technology in a certain way for a certain period of time, and the licensee needs to pay a fee to the licensor. In practice, the technology holder is generally called the licensor, whereas the opposite knowledge user is referred to as the licensee. Since 2001, SIPO has been authorized by legislation to register technology licensing contracts within three months after them being signed by the licensor and licensee. The data used in this paper is obtained from the State Intellectual Property Office of China (SIPO). However, the available data is only published from 2002 to 2012 by SIPO, so there is a time limit of our data.

The records of patent license contract include information such as contract filing number, patent number, patent name, license type, etc. The licensors could be individuals or firms, either domesticor abroad, but all the licensees are domestic. We search the names of the licensor and the licensee on the website of the Trade and Industry Bureau and the search engine to check the provinces where the patent licensor and the licensee are located. After excluding invalid data, there are 86,662 valid records, covering 41,691 license contracts, with a total of 76,289 patents, 19,976 licensors and 22,080 licensees (see Table 1). The licensors come from 31 provinces and territories in mainland China, Taiwan, Hong Kong, and foreign countries, but the licensees are all from 31 provinces in China.

Some prior studies have shown that mature technologies and state-of-the-art technologies have very different advantages and disadvantages for further innovation [13]. So we will study the evolutions of technology flow by analyzing the distribution of technology age of the licensed technology from the temporal perspective [14]. Technology age equals the interval between a patent being granted and being licensed. For example, if a technology has been granted in 2000 and licensed in 2005, then its technology age is 5 years. The older the patent is, the more mature the technology is, which means the technology is fully tested by the market. If the technology age is smaller, it represents a more advanced technology.

Figure 1 shows the total amount of in-licensed patents in China from 2002 to 2012. The amount of patents has increased from 265 in 2002 to 15,898 in 2012 ,

Table 1. Total number of valid data published by SIPO.

\begin{tabular}{cccccc}
\hline & Valid record & Contract & Patent & Licensor & Licensee \\
\hline Number & 86,662 & 41,691 & 76,289 & 19,976 & 22,080 \\
\hline
\end{tabular}




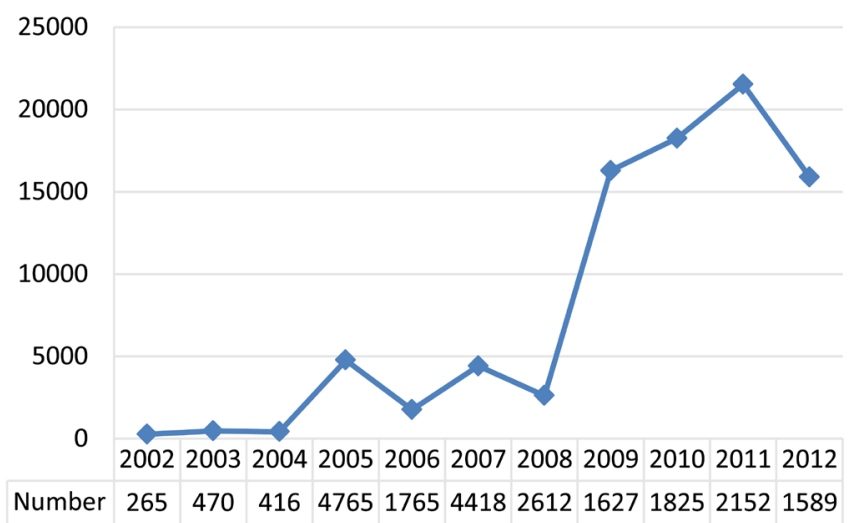

Figure 1. Annual number of technologies recorded in the SIPO, 2002-2012.

almost an increase of 60 times. And there are three stages of the evolutions of the distribution. In the first stage, only less than 500 patents are licensed out each year from 2002 to 2004. While according to the China Statistical Yearbook, the number of patents granted exceeded 100,000 each year from 2002 to 2004. This reflects the fact that the transfer of patented technology has not been paid enough attention. And technology licensing is not common as a channel for technology transfer then. In the second stage, the number of licensed technology increased rapidly but unsteadily from 2005 to 2008 . This is mainly due to the rise of optical disc technology and the vacancy in the domestic optical disc technology market, which requires the import of advanced technologies in large quantities to make up for domestic technological gaps. In the third stage, the number of licensed technology increased rapidly and steadily after 2008, which indicates that patent licensing has received widespread attention as a technology transfer channel.

\section{Licensor}

Most existing studies focus mainly on the supply side of technology transfer in which case regions in China are the licensees, but seldom on the demand side. Thus, we intend to empirically explore the overall trend, the evolutions of temporal and geographical distribution of technology transfer from the perspectives of licensor.

\subsection{Types of Licensor}

According to Wang's classification method, licensors are classified as four types, including individuals, firms, research institutes and universities [8]. We find that most of the technologies licensed before 2008 come from firms, and after 2008, individuals are the main supplier of patented technology (see Figure 2). In 2011, as many as 11,912 patents are exported by individuals. Research institutions and universities tend to publish papers and apply for patents to improve innovation performance. They are less involved in the commercial use of their own technologies. 


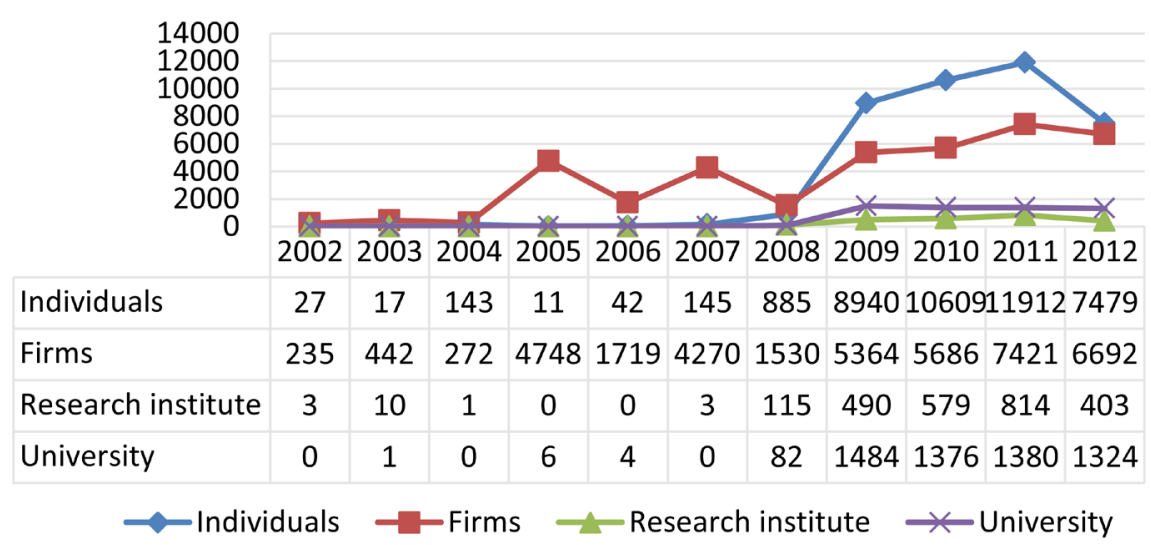

Figure 2. The distribution of outward technologies by licensor type (in absolute value), 2002-2012.

Figure 3 shows the respective percentage of different types of licensor based on the total number of licensed patents. We find that individuals and firms are the main exporters of patented technologies. It's usually difficult for individuals to commercialize the technology they hold, so they tend to license the technology out, rather than holding it for long periods of time. While firms are for-profit organizations, and they often quickly put their patented technology on the market and realize their maximized commercial benefits.

\subsection{Types of Technology}

There are three types of patent in China, including invention, utility model and design. And different types of technology contain different levels of innovation, of which inventions have the highest degree of innovation and design the lowest degree [15]. Figure 4 shows the distribution of various types of outward technology in terms of absolute value from 2002 to 2012. We find that the amount and growth rate of the three types of technology exported by regions within China is very small before 2008, and the amount of the three types of outward technology increases rapidly after 2008 , especially utility models.

We further analyze the types of patents output by different types of licensors and the result is presented in Figure 5. It indicates that although universities and research institutions do not have an advantage in the number of outward technologies; most of the technologies provided are highly innovative inventions. Besides, the type of technologies that are mainly exported by enterprises and individuals are utility models, which are not so innovative, but can be quickly put into the market to generate economic benefits and realize the commercial use of technology. This is consistent with our previous analysis results.

\subsection{Temporal Distribution}

Licensors have a choice to license out whether mature technologies or state-of-the-art technologies. In the case of entities within China as licensors, we find the technology age of outward technologies exported by domestic individuals 


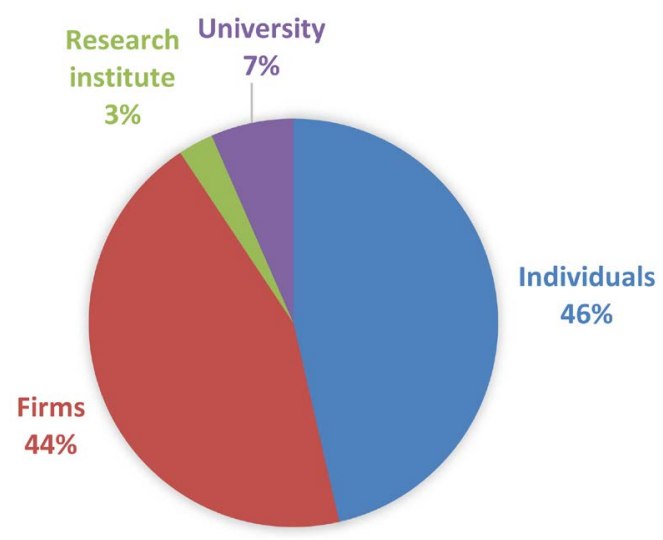

Figure 3. The distribution of outward technologies by licensor type (in percentage), 2002-2012.

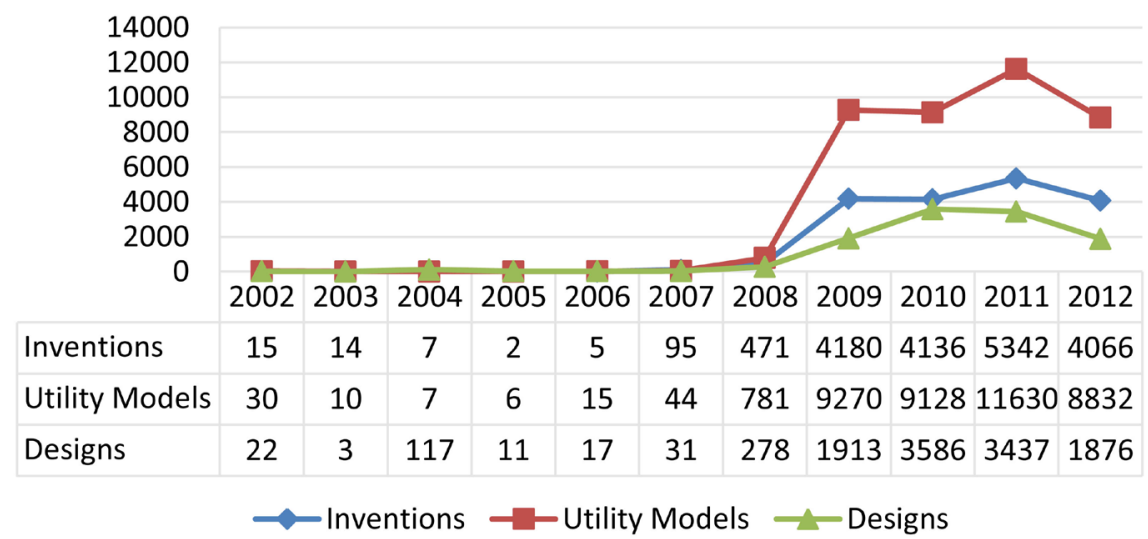

Figure 4. The distribution of outward technologies by patent type, 2002-2012.

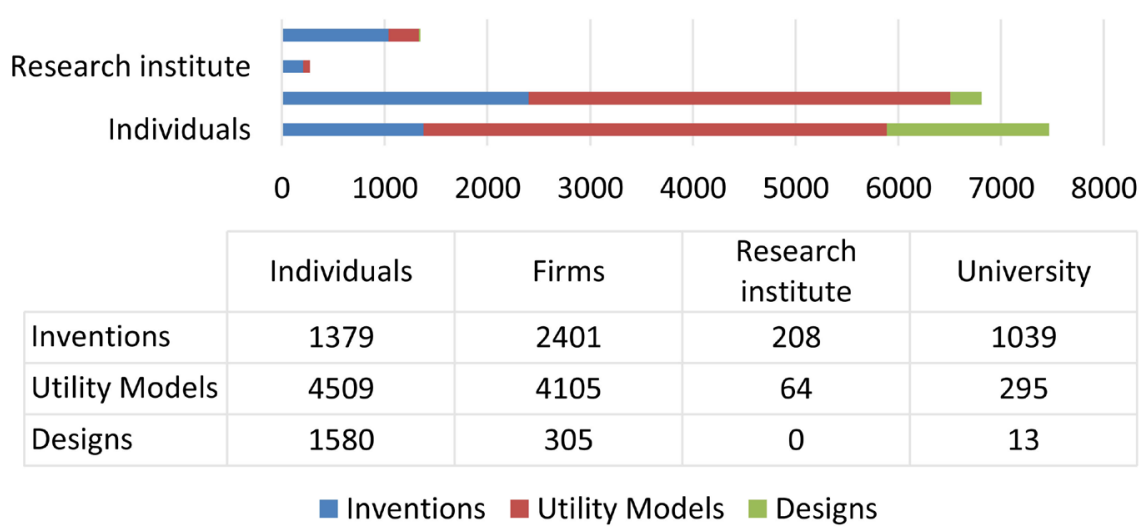

Figure 5. The distribution of different types of outward technologies in terms of licensor type in 2012 .

and organizations has gradually declined, from the highest of 4.4 to 2.6 (see Figure 6). While in 2004, the technology age suddenly dropped. This is due to the relatively low percentage of invention exported in 2004, which only makes up $43 \%$, and most of the outputs are utility model patents and design patents with shorter technology life cycles. 


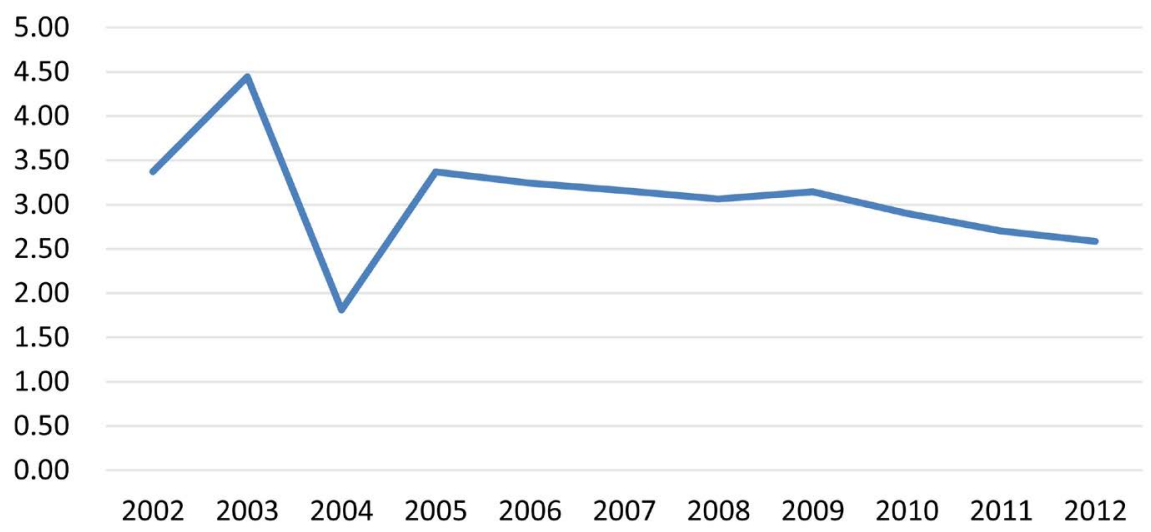

Figure 6. Average age of outward technologies, 2002-2012.

Furthermore, we use the data of 2012 to analyze the distribution of technology age of outward technologies exported by different types of licensors. The result shows that whether it is individual or organizations, they will hold most of their technologies no more than 3 years (see Figure 7). Moreover, there are some different trends when it comes to different types of licensor. For example, individuals tend to license out most of their technologies within first year, while firms prefer 2 years. As for research institute and university, the duration is 3 years.

The reason is consistent with the analysis above. Individuals have difficulty in obtaining the commercial value from their technologies, and they have to bear the annual fee for the patent that increases as time goes by. Therefore, they will choose to license their technologies out as soon as possible. While firms will balance the expected return on technology and the maintenance cost to decide whether to hold the technology, and firms also have the ability to put technology into production, so it will retain its own technology for a longer time. As for research institute and university, they will choose to hold their own technology for a much longer period of time for the purpose of research and innovation.

\subsection{Spatial Distribution}

From the perspective of the licensors, it is interesting to know where the domestic technologies go. Figure 8 shows the total distribution of outward licensing (in terms of percentage) based on the location of the licensees. We find that within-province technology licensing takes the main role and there is almost no technology being licensed abroad. This finding indicates that technology transfer in China is very localized.

\section{Licensee}

It is also important to know how the distribution evolves when it comes to the perspective of the demand side of the technology transfer transaction. So this study will analyze the overall trends, the temporal and geographical distribution of technology transfer from the perspective of licensee. 


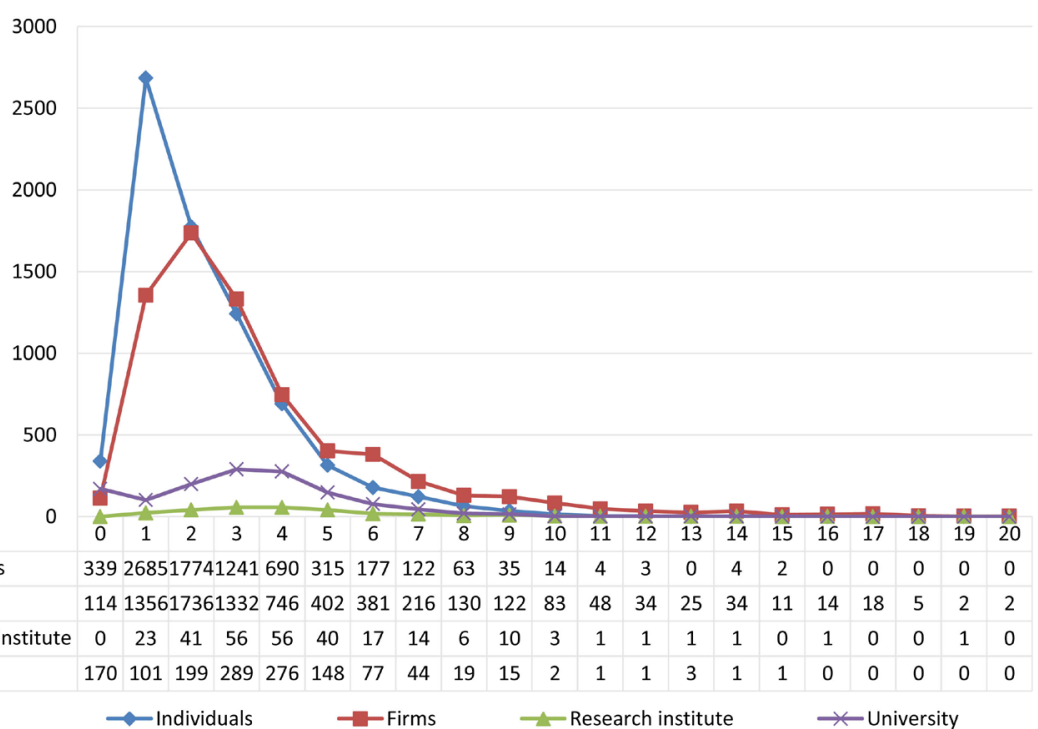

Figure 7. The distribution of technology age by licensor type, 2002-2012.

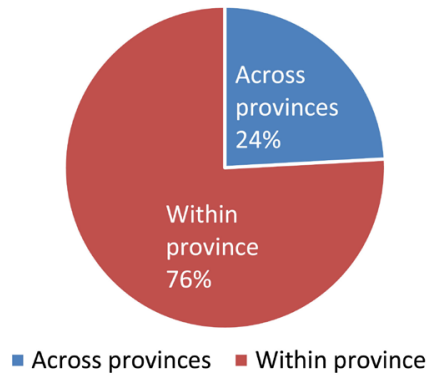

Figure 8. The geographical distribution of outward technologies, 2002-2012.

\subsection{Types of Licensee}

We analyze the distribution of different types of licensee by the total number of in-licensed technologies. The result is shown in Figure 9 (in terms of percentage).

Unlike licensors, $97 \%$ of licensed technologies flow into firms. This finding suggests that enterprise is an effective channel for patented technology to enter the market to achieve commercial benefits.

\subsection{Types of Technology}

This study also investigates the distribution of different types of in-licensed technologies from the perspective of licensee. The result shows that the growth of the three types of technologies is very slow from 2002 to 2004 (see Figure 10). And there is an unsteady increase of invention patents from 2005 to 2007. However, during the last four years, utility models are the primary licensing type, almost three times the number of designs.

\subsection{Temporal Distribution}

Chinese licensees have a choice to import old or new technologies. We analyze 


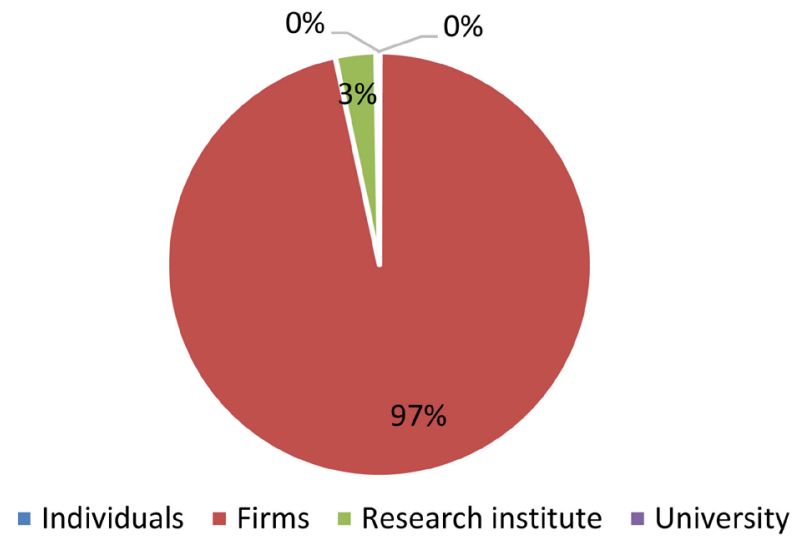

Figure 9. The distribution of inward technologies by licensee type, 2002-2012.

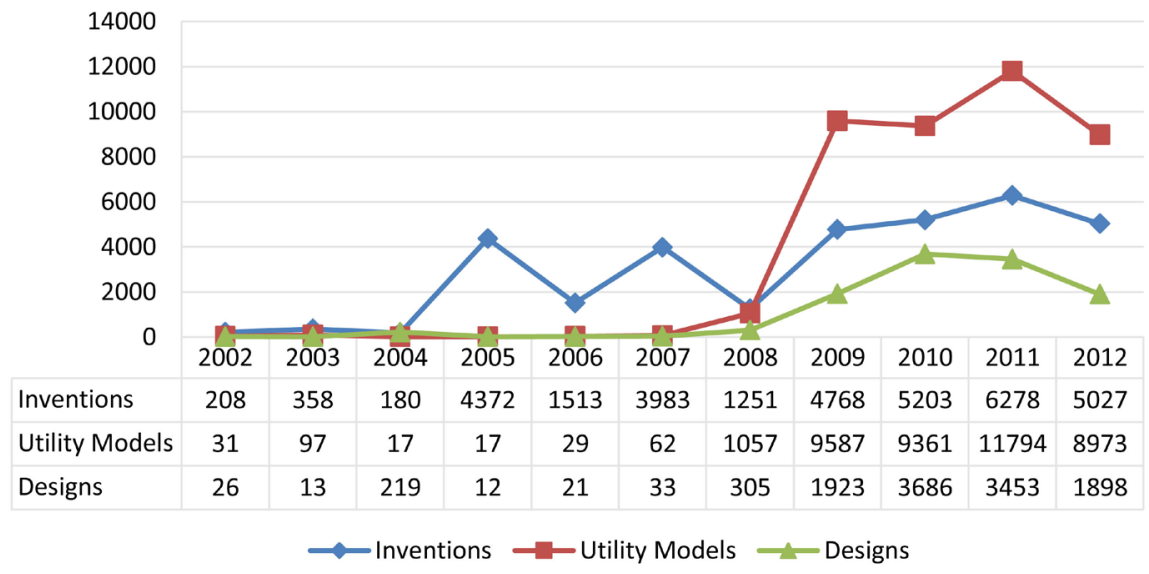

Figure 10. The distribution of inward technologies by patent type, 2002-2012.

the evolution of the average technology age of inward patents in China from 2002 to 2012 to find the preference of licensees. The result shows that Chinese licensees have gradually shifted their focus on newer technologies (see Figure 11). The average age of inward technologies during the period of 2005-2007 has shown a significant upward trend, due to a large number of mature foreign invention patents imported at that time. While after 2008, the average technology age is drastically reduced, approaching 3 years. This shows that one hand it is easier to acquire novel technologies in the technology market. On the other hand, now firms have enough technological capabilities to absorb and utilize innovative technologies to improve their own innovation capabilities.

Figure 12 shows the distribution of in-licensed technologies at every age in terms of absolute number. We find that most of the technologies are licensed within the first 3 years and starting from the third year, there is a rapid decline in the licensing of patents as time goes by.

Regarding the accumulated distribution of technology age, we find that $60 \%$ of patents are licensed out within the first 3 years after being granted by SIPO (see Figure 13) and 90\% of patents are licensed out within 8 years. On one hand, the maintenance costs of patents will increase with time, on the other hand, the 


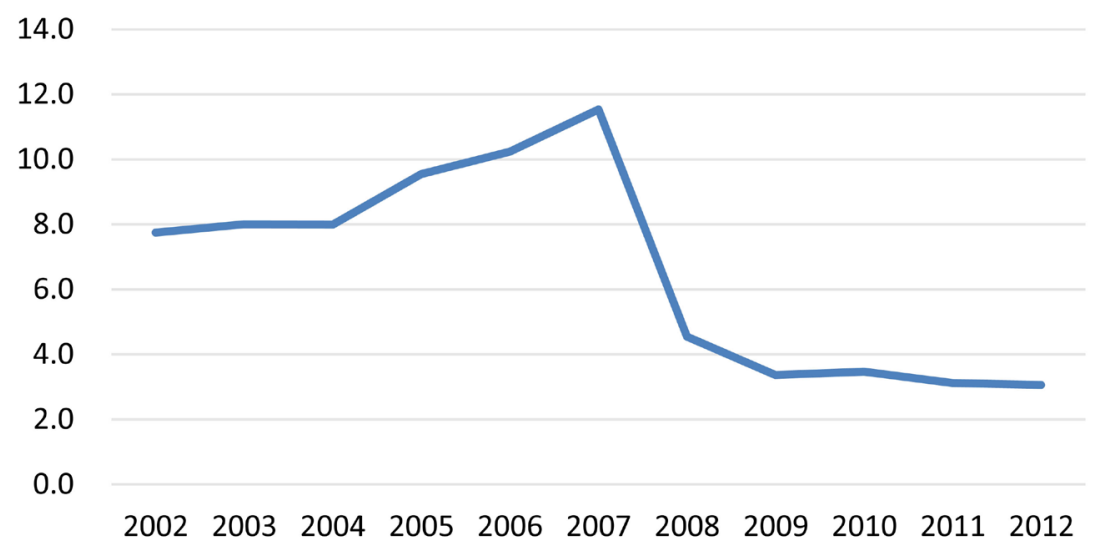

Figure 11. Average age of inward technologies, 2002-2012.

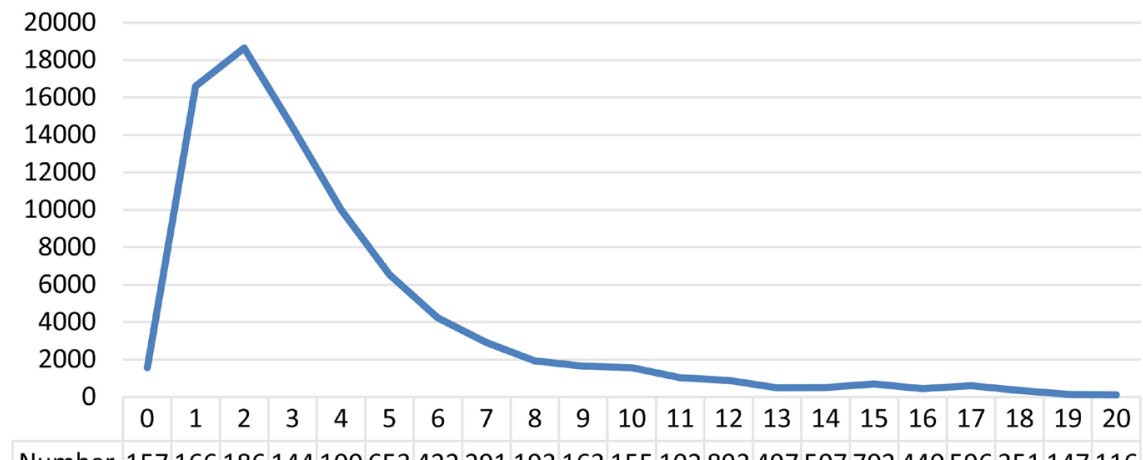

Number 157166186144100653422291193163155102893497507702440596351147116

Figure 12. The distribution of age of inward technologies, 2002-2012.

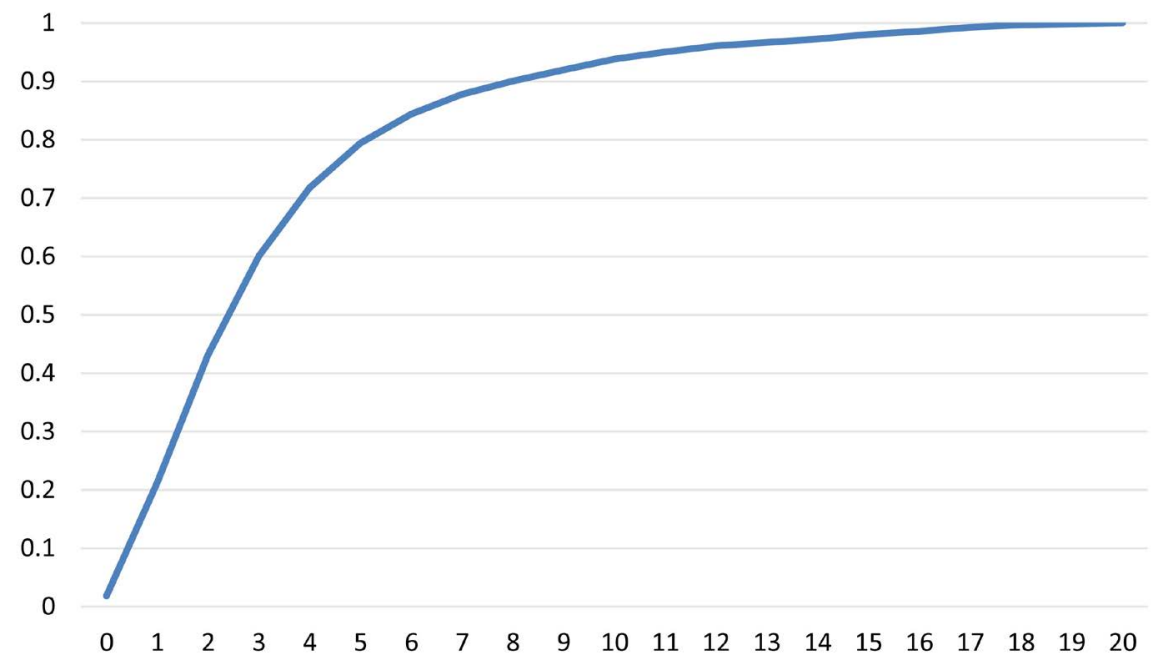

Figure 13. Accumulated percentage of technology age of inward patents, 2002-2012.

market value of technologies will gradually decline as time goes by. So the technology owners will not hold their technologies for too long.

In order to investigate the licensees' tendency to the newness of different types of patents, this paper further analyzes the age of technologies of different types. The results are shown in Figure 14. The technology age of foreign patents is 


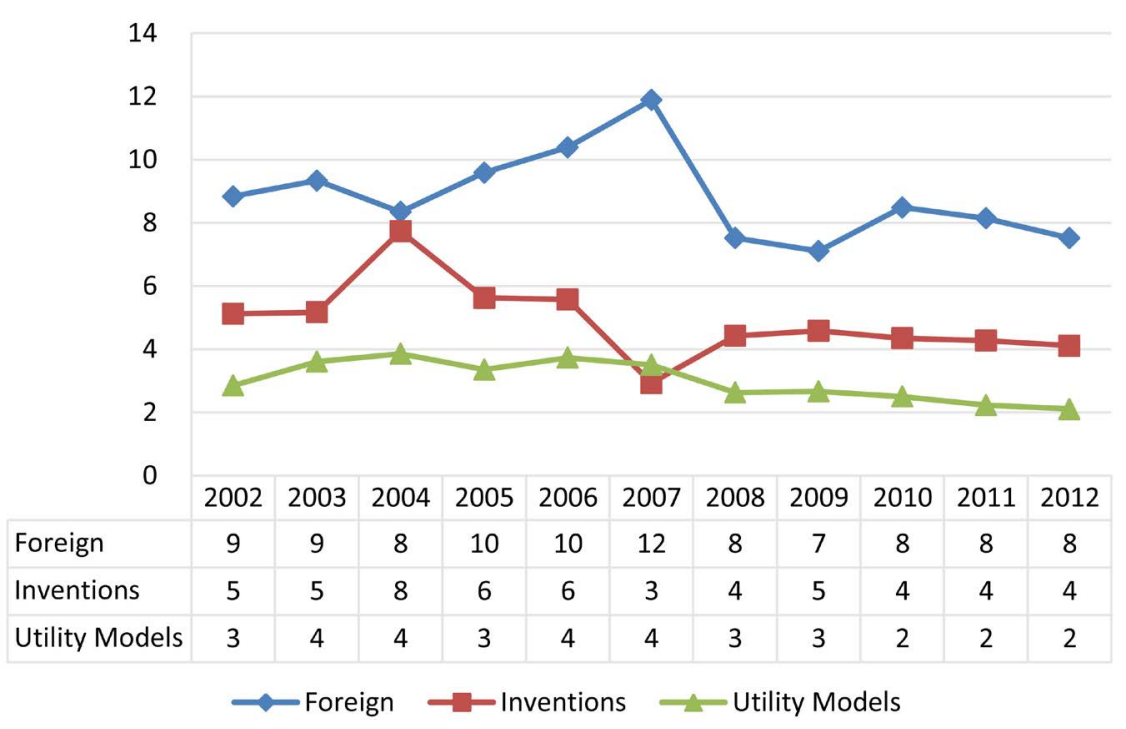

Figure 14. The average age of inward technology by patent type, 2002-2012.

generally higher than that of inventions and utility models, and the technology age of inventions is generally higher than that of utility models, except for 2007. This analysis also further validates that different types of technologies have different life cycles and different rate of technology obsolescence.

\subsection{Spatial Distribution}

Licensees may import technologies from different regions. Since China has been promoting an "indigenous innovation" policy since 2006, it will be interesting to see whether the source of technology licensing changed. Figure 15 and Figure 16 show the distribution of different regions of licensors (in absolute value and percentage, respectively). It indicates that before 2008 foreign technology market is the main supplier of technology, while after 2008, the inward technologies become much more localized, especially within province. This may be due to the development of the domestic technology market and the guiding role of indigenous innovation policy, resulting in technology search much more localized.

We find that from 2005 to 2007, foreign technologies account for more than 95\% of the total amount (see Figure 16), indicating that domestic technology market has a strong dependence on foreign technology. However, the trend changes after 2008, with over $70 \%$ of inward technologies coming from within provinces, showing that domestic technology market is capable to meet the needs of demand side of technology transfer trade.

\section{Conclusions}

This paper empirically analyzes the evolution of distribution of technology transfer in China, using the data of patent licensing contracts published by the State Intellectual Property Office of China (SIPO) from 2002 to 2012. We study the rules of technology licensing activities from the perspectives of licensor and licensee respectively. The results of the analysis are as follows. 


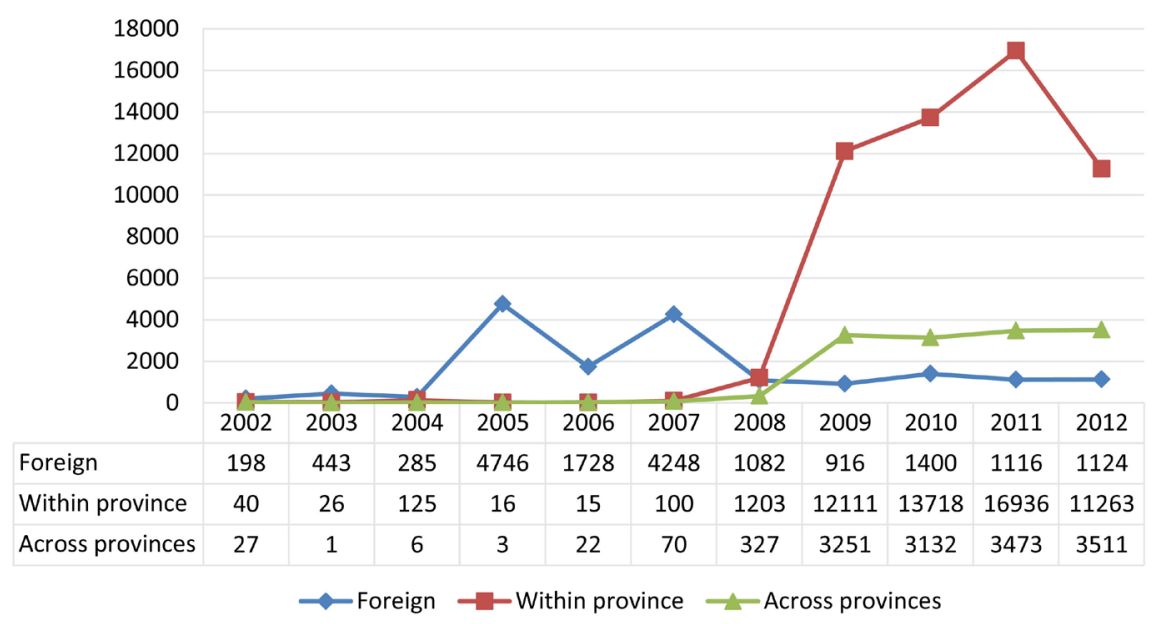

Figure 15. The distribution of inward technology by geographical sources (in absolute value), 2002-2012.

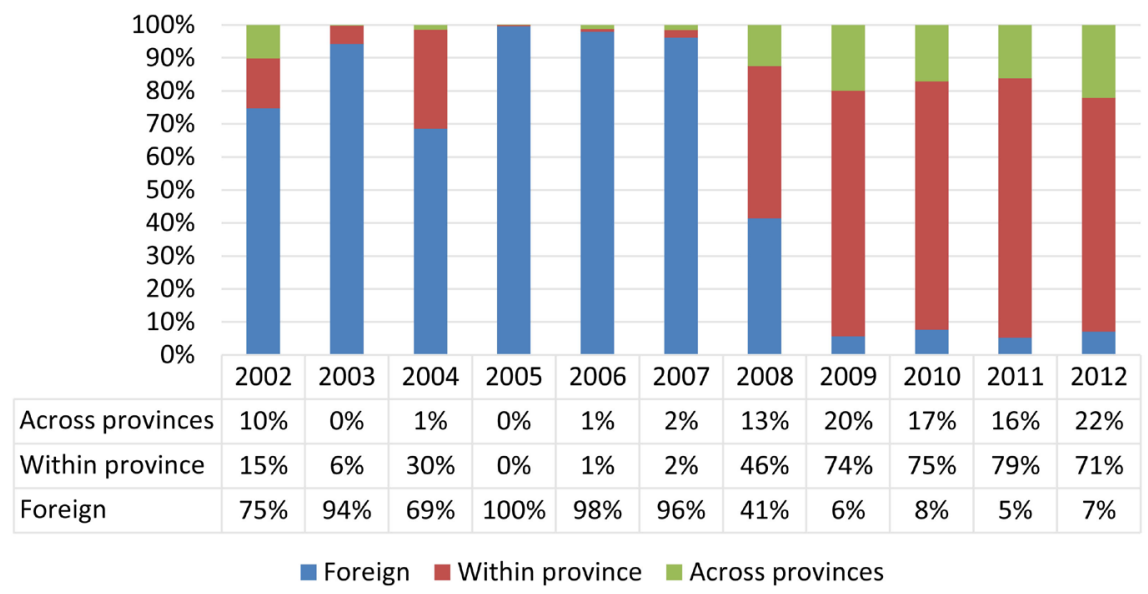

Figure 16. The distribution of inward technology by geographical sources (in percentage), 2002-2012.

On the overall trends, the total amount of technologies received in China has increased by nearly 60 times from 2002 to 2012 . There are three stages of the whole evolution. From 2002 to 2004, no more than 500 patents are received every year, while from 2005 to 2007 , the number of patents has increased a lot, by more than 10 times, with great fluctuations. Then, after 2008, the number of patents shows a steady and rapid growth trend. On one hand, our results reflect that the system of technology trade market has gradually improved, and technology information has become more transparent and open. On the other hand, patent licensing has gradually received wide attention as an important technology transfer channel. Moreover, different types of patents also show different trends, reflecting the change in demand for technology in the Chinese technology market, and utility model patents that can be rapidly put into production to obtain commercial benefits are valued by the market gradually.

From the perspective of licensor, firm is the main licensor type before 2007, while individuals become the main technology supplier after 2008. In the total 
number of patents, individuals and firms provide almost half of the total respectively. As for the type of technology, most of the outward technologies provided by individuals and firms are utility model patents, while most of the technologies provided by universities and research institutes are highly innovative invention patents.

Unlike the situation of licensor, $97 \%$ of licensees are firms, indicating that the main intention of technology transfer is to put technology into the market, generate benefits and realize commercial value.

As for the temporal distribution, technology age shows an overall downward trend from 2002 to 2012 . About $60 \%$ of the technologies are licensed within the first three years, and the chance of technology being licensed decreases over time. It shows that the speed of technology upgrading is accelerating, and the market value of technology is declining with time. Therefore, when funds are limited, the licensees should choose to import newer technologies.

This study also reveals that most of the inward technologies come from foreign countries before 2007, while domestic suppliers take the leading role after 2008. This phenomenon of the evolution in the geographical distribution indicates that the technologies held by the domestic technology market now are able to meet its own needs and China's indigenous innovation policy makes technology search more localized.

In summary, this study analyzes the temporal and geographical distribution of technology transfer, not only from the perspective of licensee, but also in terms of licensor, extending the existing literature on knowledge transfer.

In practice, these findings have strong implications for policy-making and firm managers. First, they help policy-makers to address the specific external technology needs of the different regions and types of organizations. Second, this study not only helps the supplier of the technology, but also the demand side of technology transfer to make choices about the technology trade.

Although we emphasize our contribution to visualizing knowledge space of the knowledge value chain, there are still several limitations that deserve to be addressed in future studies. Firstly, this study only empirically analyzes the temporal and geographical distribution of technology transfer, while there are still technical and cognitive dimensions to be discussed. Secondly, this article only explores the flow of knowledge through the patent licensing, while there are many other channels of technology transfer, such as FDI and business alliances, remaining to be investigated.

\section{References}

[1] Sun, Y.F. and Du, D.B. (2010) Determinants of Industrial Innovation in China: Evidence from Its Recent Economic Census. Technovation, 30, 540-550. https://doi.org/10.1016/j.technovation.2010.05.003

[2] Lee, J.S., Park, J.H. and Bae, Z.T. (2017) The Effects of Licensing-In on Innovative Performance in Different Technological Regimes. Research Policy, 46, 485-496. https://doi.org/10.1016/j.respol.2016.12.002 
[3] Martinez, C. and Penas, G. (2013) Patenting and Licensing by Spanish Firms: Available Survey Evidence. World Patent Information, 35, 296-304. https://doi.org/10.1016/j.wpi.2013.06.003

[4] Johnson, D.K.N. (2002) Learning-by-Licensing: R \& D and Technology Licensing in Brazilian Invention. Economics of Innovation and New Technology, 11, 163-177. https://doi.org/10.1080/10438590210904

[5] Bin, G. (2008) Technology Acquisition Channels and Industry Performance: An Industry-Level Analysis of Chinese Large- and Medium-Size Manufacturing Enterprises. Research Policy, 37, 194-209. https://doi.org/10.1016/j.respol.2007.11.004

[6] Chittoor, R., Aulakh, P.S. and Ray, S. (2015) Accumulative and Assimilative Learning, Institutional Infrastructure, and Innovation Orientation of Developing Economy Firms. Global Strategy Journal, 5, 133-153. https://doi.org/10.1002/gsj.1093

[7] Wang, Y. and Li, Y.J. (2015) Licensing Foreign Technology and the Moderating Role of Local R \& D Collaboration: Extending the Relational View. Journal of Product Innovation Management, 32, 997-1013. https://doi.org/10.1111/jpim.12246

[8] Wang, Y.D., Pan, X., Wang, X.Y., et al. (2014) Visualizing Knowledge Space: A Case Study of Chinese Licensed Technology, 2000-2012. Scientometrics, 98, 1935-1954. https://doi.org/10.1007/s11192-013-1135-0

[9] Liu, X. and Ma, F. (2013) Transfer and Distribution of Knowledge Creation Activities of Bio-Scientists in Knowledge Space. Scientometrics, 95, 299-310. https://doi.org/10.1007/s11192-012-0827-1

[10] Chen, X. and Sun, C. (2000) Technology Transfer to China: Alliances of Chinese Enterprises with Western Technology Exporters. Technovation, 20, 353-362. https://doi.org/10.1016/S0166-4972(99)00148-0

[11] Chung, M.Y. and Lee, K. (2015) How Absorptive Capacity Is Formed in a Latecomer Economy: Different Roles of Foreign Patent and Know-How Licensing in Korea. World Development, 66, 678-694. https://doi.org/10.1016/j.worlddev.2014.09.010

[12] Chesbrough, H. (2006) New Puzzles and New Findings. In: Chesbrough, H., Vanhaverbeke, W. and West, J., Eds., Open Innovation: Researching a New Paradigm, Oxford University Press, Oxford, 15-34.

[13] Zhao, Y.Y., Wong, P.K., Subramanian, A.M., et al. (2014) Technology Licensing and Innovation Performance: Evidence from Chinese Latecomers in High-Tech Industries. Journal of Chinese Economic and Business Studies, 12, 125-147. https://doi.org/10.1080/14765284.2014.900946

[14] Rockett, K. (1990) The Quality of Licensed Technology. International Journal of Industrial Organization, 8, 559-574. https://doi.org/10.1016/0167-7187(90)90030-5

[15] Fosfuri, A. (2006) The Licensing Dilemma: Understanding the Determinants of the Rate of Technology Licensing. Strategic Management Journal, 27, 1141-1158. https://doi.org/10.1002/smj.562 